\title{
GIS-based habitat model to predict potential areas for the upcoming occurrences of an alien invasive plant, Mimosa pigra $\mathrm{L}$.
}

\author{
Thai Son Le ${ }^{1 *}$, Pham Thi Kim Thoa ${ }^{2}$ and Nguyen Van Tuan ${ }^{3}$
}

Le, T.S., Thoa, P.T.K, Tuan, N.V. 2019. GIS-based habitat model to predict potential areas for the upcoming occurrences of an alien invasive plant, Mimosa pigra L. - Forestry Studies | Metsanduslikud Uurimused 70, 31-43, ISSN 1406-9954. Journal homepage: http://mi.emu. ee/forestry.studies

\begin{abstract}
Incursions of Mimosa pigra L., a super-invasive plant, were detected in Hoa Vang district, Da Nang city, Vietnam. This invasive species posed threats to the local agricultural and natural areas, especially to Ba $\mathrm{Na}$ - Nui Chua Nature Reserve located in the district. In this study, a habitat model was developed to predict potential areas for the upcoming occurrences of the plant. Detected locations of the species were analyzed in association with seven environmental layers (15 m spatial resolution), which characterized the habitat conditions facilitating the plant incursion, to calculate a multivariate statistic, Mahalanobis distance $\left(D^{2}\right)$. Mimosa occurrences were divided into subsets of modelling (for model construction) and validating data (for selecting the best model from replicate runs). The model performance was tested using a null model of 1,000 random points and indicated a significant relationship between $D^{2}$ values and mimosa occurrence. The $D^{2}$ model performed markedly better than the random model. The null model in combination with the entire dataset of mimosa locations was also used to identify the threshold $D^{2}$ value. Using that threshold value, $99.5 \%$ of existing mimosa locations were detected and $20.3 \%$ of the study area was determined as high-risk areas for mimosa occurrence. These identified high risk areas would make an important contribution to the local alien invasive species management. Given the potential threats to these species from illegal harvesting, that information may serve as an important benchmark for future habitat and population assessments. The spatial modelling techniques in this study can easily be applied to other species and areas.
\end{abstract}

Key words: GIS, habitat modelling, Mahalanobis distance, predictive model.

Authors' addresses: ${ }^{1}$ Vietnam National University of Forestry, Xuan Mai Town, Chuong My District, Hanoi, Vietnam; ${ }^{2}$ The University of Da Nang - University of Science and Technology, Da Nang, Vietnam; ${ }^{3}$ Department of Silviculture Foundation, Silviculture Research Institute, Vietnam Academy of Forest Sciences, Hanoi, Vietnam; Authors ${ }^{1,2}$ contributed equally to this work; *e-mail: thaisonfuv@gmail.com

\section{Introduction}

Vietnam is a tropical country with rich biodiversity, however, being threatened by numerous invasive species (Pham, 1999; Thu, 2003; Le, et al., 2011; Tan et al., 2012; MNRE \& MARD, 2013). Among them, $\mathrm{Mi}$ mosa pigra L. is a super-invasive species 
with its natural distribution in tropical America and was first recognized in Vietnam in 1979 (Walden et al., 1999). This species has been identified as one of the most harmful plants over the world as it is listed in many invasive species charts, such as 100 of the world's worst invasive alien species (ISSG \& IUCN, 2017) and the list of invasive species in Southeast Asia (Pallewatta et al., 2003). Particularly in Vietnam, this species was emphasized as an invasive species according to the circular No. 27/2013TTBTNMT (MNRE \& MARD, 2013).

In Vietnam, numerous studies have been published on managing Mimosa pigra (Walden et al., 1999; Triet et al., 2001; Triet et al., 2002; Thu, 2003; Tan et al., 2012; Thai, 2016). However, these studies predominantly focused on the status of the invasive species and how to control it, including proposing managing solutions, such as eradicating the species or reducing its damage to the local natural and agricultural ecosystems (Cam et al., 1997; Thanh et al., 1998; Walden et al., 1999; Lam et al., 2001; Triet et al., 2002; Son et al., 2004). At the same time, it is clear that prevention is better than cure. Indeed, early detection and rapid response pose to be a superior approach to invasive species management (USDA Forest Service, 2003) which has not been applied in Mimosa pigra management in Vietnam.

Hoa Vang district, Da Nang city, Vietnam is a sub-urban area with a high rate of rural development. Recently, the incursion of Mimosa pigra has been detected in several areas within this district, especially in residential and construction areas. In addition, these infested areas are in the buffer zone of Ba Na - Nui Chua Nature Reserve that poses threats to the local forest and agricultural ecosystems. Early detection of the occurrence of Mimosa pigra in Hoa Vang district plays a crucial role in successfully controlling this invasive species and in minimizing its negative effects on the environment. The actual implementation of invasive species early detection will be highly dependent on accurately predicting potential areas for the next occurrences of the species. Habitat models developed in a geographic information system (GIS) may provide useful tools for examining the habitat of an introduced species and for identifying suitable conditions for its occurrence and dispersal (Rotenberry et al., 2006; Thompson et al., 2006; Le, 2018). The objective of this study was to develop and test a GIS-based modeling approach to predict the invasion risk for areas that have a high potential for the next occurrences of Mimosa pigra in Hoa Vang district, Da Nang city, Vietnam where this species recently appeared.

\section{Material and Methods}

\section{Study species}

Mimosa pigra, also known as mimosa, is a small-sized woody, much branched prickly shrub with mature height of up to $6 \mathrm{~m}$. Individuals of this species reach maturity quickly and can produce seeds soon (i.e. before becoming one year old) (Walden et al., 1999; ISSG \& IUCN, 2017). Its favourite habitats include open, moist sites (e.g. floodplains, coastal plains, and riparian areas) in a wet-dry tropical climate (Lonsdale, 1992; Walden et al., 1999). However, this species has high adaptability and resilience, enabling it to develop in a wide range of environmental conditions (Walden et al., 1999; ISSG \& IUCN, 2017). Indeed, this species can appear in adverse conditions (e.g. low precipitation of below $75 \mathrm{~mm}^{\text {year-1) }}$ and in many soil types (ISSG \& IUCN, 2017). Mimosa is likely to invade disturbed areas (e.g. construction areas, and abandoned bare land) where it may lack competitive pressure. Moreover, due to being shifted along with water flows, this species preferentially appears as clusters along the edges of reservoirs, canals, river banks and roadside ditches (Lonsdale, 1992; Walden et al., 1999; Triet et al., 2002). Growing quickly and being extremely competitive, 


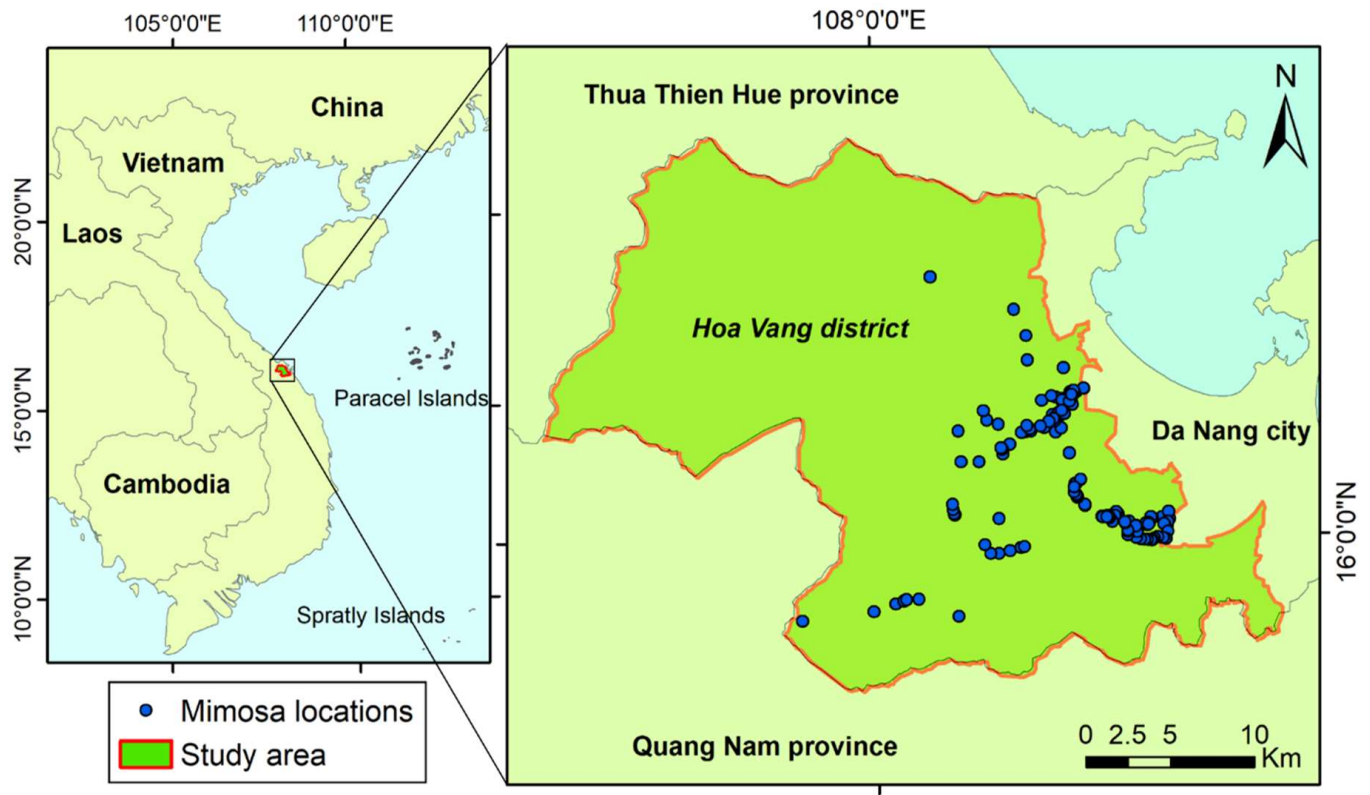

Figure 1. Locations of the study area and detected mimosa occurrences.

Mimosa pigra can easily overwhelm natural and agricultural areas as well as damage irrigational systems (Lonsdale, 1992; Walden et al., 1999; Triet et al., 2002; Son et al., 2004; ISSG \& IUCN, 2017).

\section{Study area}

This research was conducted in Hoa Vang district (i.e. area of $707.3 \mathrm{~km}^{2}$ ) and some adjacent areas to the east in Da Nang city where additional occurrences of mimosa were detected $\left(15^{\circ} 56^{\prime} \mathrm{N}\right.$ to $16^{\circ} 13^{\prime} \mathrm{N}$; $107^{\circ} 49^{\prime}$ E to $108^{\circ} 13^{\prime}$ E; GCS_WGS_1984) (Figure 1). Hoa Vang district has a typical tropical monsoon, temperate and equable climate with two separate seasons (i.e. a wet season from September to December and the remaining dry season) (Da Nang People's Committee, 2018).

Located in Hoa Vang district, Ba $\mathrm{Na}$ Nui Chua Nature Reserve with a total area of 26,751.3 ha (Vietnam Government, 2014) is a very rich source of biodiversity. Lowland evergreen forest and evergreen lower montane forest are the two main types of natural vegetation cover. The flora com- prises 793 species, belonging to 487 genera and 134 families. 19 species are listed in the Red Book of Vietnam. The fauna of $\mathrm{Ba} \mathrm{Na}$ - Nui Chua has 256 species, of which there are 61 mammals, 179 birds and 17 reptilians (belonging to 8 families) (Le et al., 2011; Da Nang People's Committee, 2018). However, the natural ecosystem within $\mathrm{Ba}$ $\mathrm{Na}$ - Nui Chua Nature Reserve has faced a significant challenge under the incoming invasion pressures of alien plants, especially Mimosa pigra.

\section{Material}

Seven environmental layers covering a range of natural and socioeconomic factors potentially associated with mimosa incursion and spread were used as predictor variables in the models (Table 1). All layers were converted to a raster format with the resolution of $15 \times 15 \mathrm{~m}$ and the projection set to UTM_WGS_1984_Zone_48N as preferred in Vietnam. Slope, aspect, solar insolation and topographic wetness index were derived from a digital elevation model (DEM). NDVI layer was calculated from 
Landsat 8 images captured at the same time of field survey.

The study area was surveyed based on a systematic $1 \times 1 \mathrm{~km}$ grid (except undisturbed natural forest areas) to record Mimosa pigra occurrences by global positioning system (GPS) receivers and unmanned aerial vehicle (UAV) images. The study used UAV DJI Mavic Ari flying at the speed of $40 \mathrm{~km} \mathrm{~h}^{-1}$ and $500 \mathrm{~m}$ of height. UAV images were captured during the automatic flights processed by the DJI GO 4 application for smartphones. Captured UAV images at the resolution of 12 megapixels were used for initial detection of mimosa to find every single area posed to be infested by mimosa. The information from these images was used as guidance for field survey to confirm the occurrences of mimosa. A database of 186 locations (Figure 1) was compiled with observed mimosa presence to develop the habitat model. Following the partition ratio calculated by the formula by Huberty (1994): $\left[1+(p-1)^{1 / 2}\right]^{-1}$ (where $p$ is the number of model variables), these points were randomly divided into two subsets of modelling (132 points) and validating (54 points) data.

Table 1. Environmental layers used as predictor variables in the Mahalanobis distance models.

\begin{tabular}{|c|c|c|}
\hline Variable & Description & Source \\
\hline Elevation & $15 \times 15 \mathrm{~m}$ digital elevation model (DEM) & Da Nang Forest Protection Department \\
\hline Slope & Slope in degrees & $\begin{array}{l}\text { Calculated from DEM using the Slope tool } \\
\text { (ArcGIS 10.4) }\end{array}$ \\
\hline Aspect & Aspect (compass bearing $0-360^{\circ}$ ) & $\begin{array}{l}\text { Calculated from DEM using the Aspect tool } \\
\text { (ArcGIS 10.4) }\end{array}$ \\
\hline $\begin{array}{l}\text { Solar } \\
\text { Insolation }\end{array}$ & An index of exposure to sunlight & $\begin{array}{l}\text { Calculated from DEM using the Hillshade tool } \\
\text { (ArcGIS 10.4) }\end{array}$ \\
\hline TWI & $\begin{array}{l}\text { Topographic Wetness Index; an index } \\
\text { of topographic control on hydrological } \\
\text { processes }\end{array}$ & $\begin{array}{l}\text { Calculated from DEM (in a watershed scale) } \\
\text { based on Beven and Kirkby (1979) }\end{array}$ \\
\hline Roads & Distance $(m)$ from the nearest road & $\begin{array}{l}\text { Calculated using data from Da Nang Forest } \\
\text { Protection Department }\end{array}$ \\
\hline NDVI & $\begin{array}{l}\text { Normalized Difference Vegetation Index; an } \\
\text { index of green vegetation cover }\end{array}$ & $\begin{array}{l}\text { Calculated from Landsat } 8 \text { image based on } \\
\text { Tucker (1979) }\end{array}$ \\
\hline
\end{tabular}

\section{Methods}

By calculating a multivariate statistic, Mahalanobis distance $\left(D^{2}\right)$, the study generated a predicting model with only presence data (presence-only model). Basically, $D^{2}$ is a multi-dimensional measure of dissimilarity between an observation (i.e. a point) and the mean of a set of observations (i.e. a data set) (Clark et al., 1993; van Manen et al., 2002; Rotenberry et al., 2006; Thompson et al., 2006). This measure is widely used to map the probability of occurrences of a species at a location by examining the similarity of environmental conditions among the habitat (Rotenberry et al., 2002; Thompson et al., 2006; Tsoar et al., 2007; Liang et al., 2014). Based on the ecological niche concept popularized by Hutchinson (1957), this statistic is used as an index of risk assessment by comparing the habitat conditions in the study area with those of the observed mimosa locations for modelling. Then, the calculation of the $D^{2}$ value for each pixel in the study area from modelling variables is based on the equation (1) (Jenness, 2009). 


$$
D^{2}=(x-m)^{T} C^{-1}(x-m)
$$

Where $D^{2}=$ Mahalanobis distance; $x=$ vector of data from modelling variables characterizing habitat conditions; $m=$ mean vector habitat characteristics from observed mimosa locations (presence data); $C^{-1}=$ inverse covariance matrix of independent variables, also from observed mimosa locations; $T=$ indicates vector should be transposed. A smaller $D^{2}$ value indicates a closer similarity between the condition in consideration and the mean condition from observed mimosa occurrences as well as a higher chance of mimosa occurring in that condition.

The $D^{2}$ calculation was performed by Land Facet Corridor Tools (Jenness et al., 2013), an extension in ArcGIS 10.4 software (ESRI Company, Redlands, California, USA). 10 replicate runs were operated using data split randomly by applying the partition ratio of modelling/validating data each run. Validating data were used to test the model without involving in model construction. For better visual illustration, $D^{2}$ values were rescaled to the range of $0-1$ by converting these values to a Chi-square distribution ( $p$-value), using the Chi-square Raster Transform function in the Land Facet Corridor Tools (Jenness et al., 2013). The maximum $p$-value of 1 would represent the lowest $D^{2}$ value (i.e. the greatest probability of mimosa incursion at the location).

To find the best $D^{2}$ model among the 10 replicate runs, predictive performances of these models were measured using the area under a receiver operator characteristic [ROC] curve (i.e. area under the curve - AUC), which is typically used for evaluation of predicting model performance (Fielding \& Bell, 1997). The results of AUC value for each $D^{2}$ model were generated by the SDMTools package within the R software version 3.2.3, a free statistical modelling program (R Core Team, 2013), using the subset of validating data in association with a set of data from 1,000 randomly se- lected background locations (i.e. null model). The $D^{2}$ model with the highest AUC value was selected as the best model for further consideration.

For prediction testing, the method of cumulative frequency graph (Pereira \& Itami, 1991; van Manen et al., 2005) was adopted using locations from all recorded occurrences and 1,000 random background points (i.e. the null model) within the study area. The $D^{2}$ values were extracted to these locations by the tool Extract Values to Points in ArcGIS 10.4 software. The percent cumulative frequency of occurrence locations against the $D^{2}$ values was graphed and compared with that of the null model. The trend lines from the graph would represent the $D^{2}$ value distributions from the high-risk area of mimosa incursion and from the whole study area. Insignificant differences between these trend lines would prove that there is an insignificant relationship between the occurrence of mimosa and $D^{2}$ values and, in other words, the result of the $D^{2}$ modelling approach is close to a random selection (Pereira \& Itami, 1991; Thompson et al., 2006).

To identify the occurrence threshold value, the $D^{2}$ value with the widest gap between the two trend lines (i.e. the two cumulative frequency distributions) was detected. Pixels with $D^{2}$ values below the threshold value would represent a greater risk of mimosa occurrence (Browning et al., 2005). In addition, the $D^{2}$ threshold value would also maximize predictive gain (i.e. the highest ratio of correct prediction; the highest precision) when indicating the greatest percentage of existed mimosa occurrences within the smallest percentage of the study area (Kvamme, 1992; Browning et al., 2005).

The modelling procedure in this study is summarized in Figure 2. 


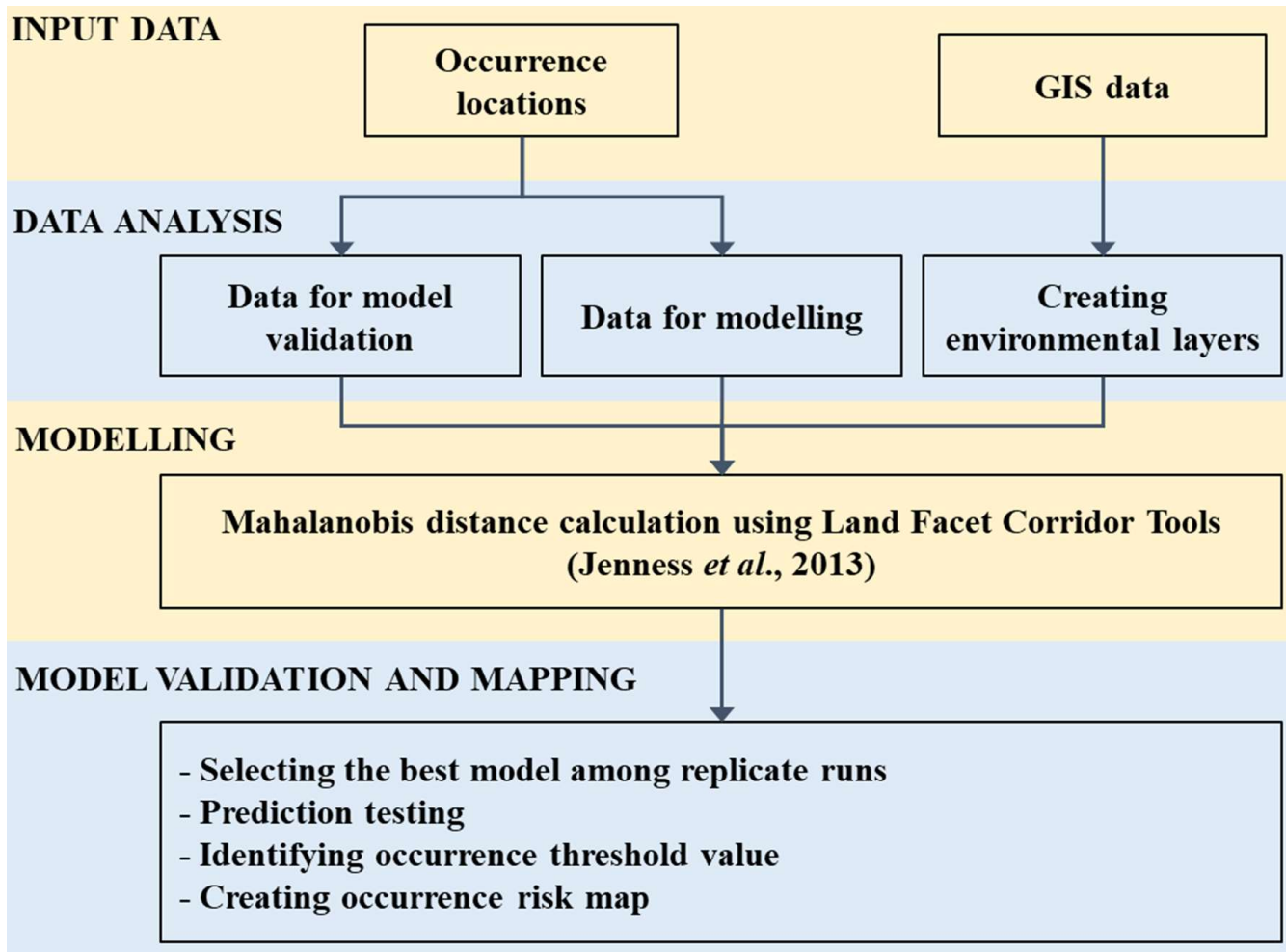

Figure 2. The modelling procedure for occurrence risk mapping.

\section{Results}

The AUC values from the $D^{2}$ models ranged from 0.83 to 0.91 which indicated relatively high predictive performance for all the models as compared to a random selection (i.e. $A U C=0.5)$. The result of the best model was used (i.e. with the highest AUC value of 0.91) for further consideration.
In general, a significant difference was detected when comparing $D^{2}$ value distributions of mimosa locations and of the entire study area (Table 2). Calculated $D^{2}$ values in the study area widely ranged from 0.03 to 59607.15 , while the maximum $D^{2}$ value at mimosa locations reaches only 71.97. The mean value over the study area was 213.09 , equal to roughly $4,250 \%$ of that for mimosa locations (5.02).

Table 2. Distribution parameters of Mahalanobis distance $\left(D^{2}\right)$ values.

\begin{tabular}{lccc}
\hline$D^{2}$ value & Mimosa locations & Study area & Null model \\
\hline Min & 0.299 & 0.030 & 0.409 \\
Max & 71.971 & 59607.152 & 2946.089 \\
Mean & 5.019 & 213.088 & 582.373 \\
Standard error & 0.567 & 0.176 & 17.25825 \\
\hline
\end{tabular}




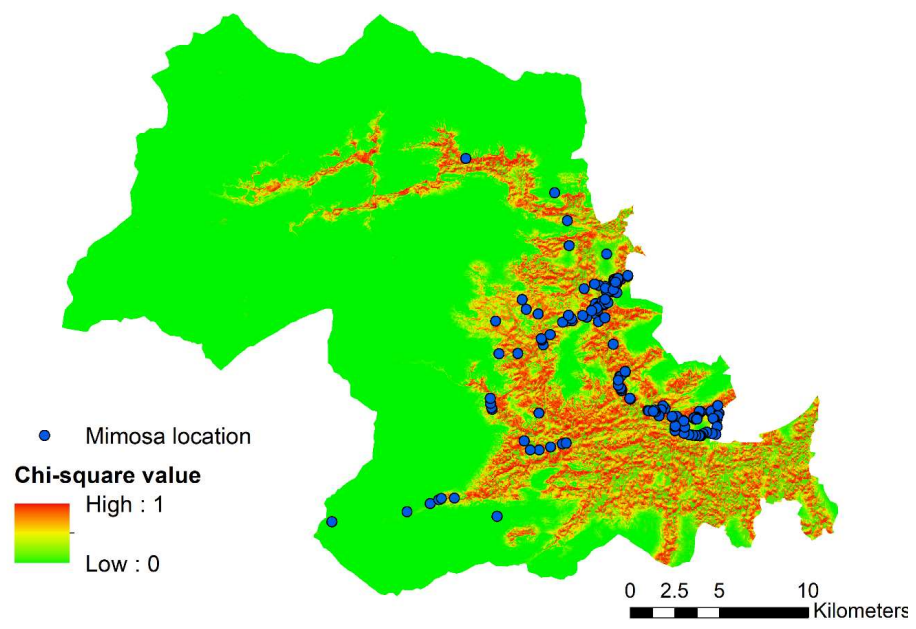

Figure 3. Risk map of mimosa occurrence by the Chi-square value. Low Chi-square values represent low probabilities of mimosa occurrences.

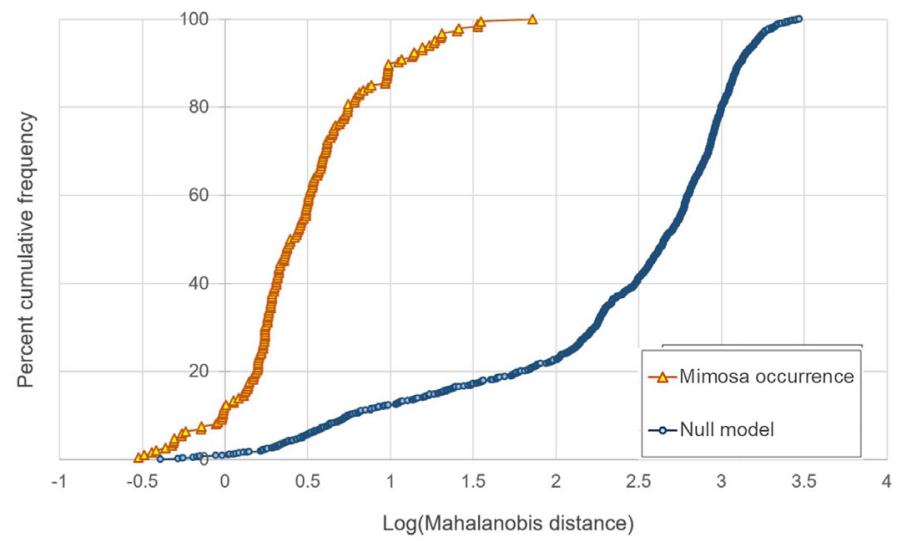

Figure 4. Cumulative frequency distribution of Mahalanobis distance values (x-axis logarithmic) for the 186 mimosa locations and the 1,000 random locations of the null model.

Figure 3 shows the distribution of the $p$-value in Hoa Vang district where high $p$-values (i.e. low $D^{2}$ values) were concentrated in locations to the east and southeast of the study area (Figure 3). These locations coincide with low elevation and slope, and appear closer to roads and streams.

The cumulative frequency distribution graph shows a great difference between the figures of the mimosa locations and of the null model (Figure 4) that prove a considerable relationship between the occurrence of mimosa and $D^{2}$ values. In gen- eral, the model successfully delineated locations susceptible to Mimosa pigra within the study area.

To identify the threshold value, the graph in the $D^{2}$ value scale from 0-80 (Figure 5) was considered. Figure 5 indicated that the threshold value to define the high risk of mimosa occurrence was no more than 35.1. With that threshold value, the model correctly detected $99.5 \%$ of the mimosa occurrences corresponding with only $17.6 \%$ of the examined random locations (Figure 5). 


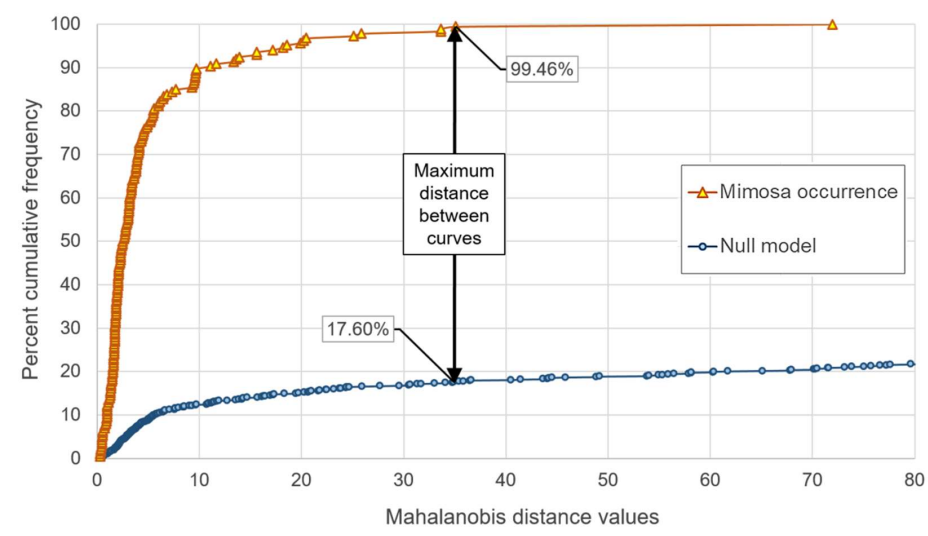

Figure 5. Cumulative frequency distribution of Mahalanobis distance $\left(D^{2}\right)$ values for the mimosa locations and the null model in the $D^{2}$ value scale from $0-80$. The maximum predictive gain for the model (i.e. maximum distance between curves) was identified at the threshold of 35.1 (i.e. arrow).

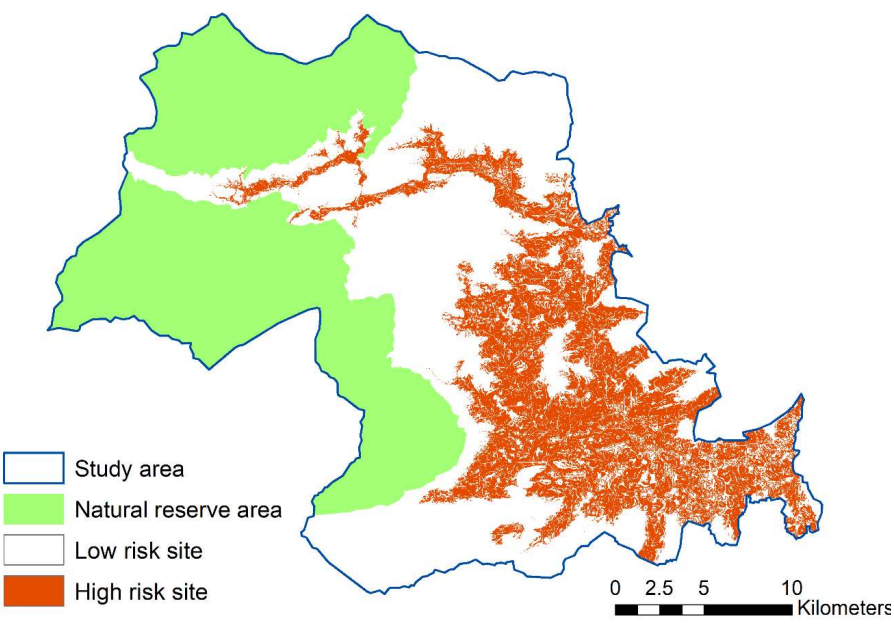

Figure 6. Map of mimosa occurrence risk. Mahalanobis distance values were reclassified using the identified threshold of 35.1. Values below the threshold indicate high-risk sites.

The identified threshold used as the break value to reclassify the $D^{2}$ layer into two classes: (1) High risk of mimosa occurrence: areas with $D^{2}$ values below the threshold value; (2) Low risk of mimosa occurrence: area with $D^{2}$ values higher than 35.1 (Figure 6). After reclassification, an area of roughly $143 \mathrm{~km}^{2}(638,013$ pixels) was in a high risk which represented $20.3 \%$ of the study area $\left(707.3 \mathrm{~km}^{2}\right)$.

\section{Discussion}

There are numerous methods using multivariate analyses in association with environmental factors to predict species distribution, such as logistic regressions (Peeters \& Gardeniers, 1998; Higgins et al., 1999; Manel et al., 1999), Gaussian logistic regressions (Legendre \& Legendre, 1998), discriminant analyses (Livingston et 
al., 1990), artificial neural networks (Spitz \& Lek, 1999), genetic algorithm for ruleset prediction (Peterson, 2001), generalized linear models (GLM) (McCullagh \& Nelder, 1989; Guisan et al., 2002), and generalized additive models (GAM) (Guisan et al., 2002). However, these methods require not only presence but also absence data. Using these methods, researchers often face challenges when it is difficult to confirm whether a species is absent at a location and false absence may harm the accuracy of prediction.

To solve the problem, Hirzel et al. (2002) used the ecological niche factor analysis (ENFA) to generate habitat-suitability maps with only presence data. Furthermore, ENFA was combined with GAM (Zaniewski et al., 2002) or GLM (Engler et al., 2004) for predicting species distribution from presence and pseudo-absence data when absence data were not available. Without using absence data or even pseudo-absence data, the maximum entropy species distribution model (MaxEnt) (Phillips et al., 2006; Phillips \& Dudik, 2008; Elith et al., 2011) uses presence-only data to produce a continuous probability of relative habitat suitability. However, these methods only answered the question of how the study areas were suitable for the target species.

To evaluate the probabilities of species occurrence, especially invasive species, the approach of the Mahalanobis distance (MD) model evaluates the risk of incursion using presence-only data. Presence data are locations infested by the alien species and such locations can be considered as $100 \%$ risk of occurrence. Hence, when the MD model evaluates how the environmental conditions at all locations in the study area are similar to that at the infested locations; it also represents the risk of species occurrence over the study area. In general, the Mahalanobis distance model as built in this study is recommended in situations where a species is recently introduced to an area and has a high potential to further establish itself over the area. It is noticed that the MD model approach requires presence data as many as possible because a small number of occurrences may not adequately describe all the environmental conditions with a high risk of incursion.

The model in this study may face uncertainties in terms of modelling/validating data that are yet to be resolved. These uncertainties include a wide range of errors, such as GPS errors, model variable errors and mimosa detection errors (i.e. missing a number of existing mimosa populations in field survey). Although these errors usually appear to be unbiased, they, if occurred, still affect the model performance and model validation. Particularly for mimosa, this species often grows together as clusters that cover a large area. Such large areas can contain different conditions in terms of the habitat model variables that a single point cannot describe. As the habitat variables were mapped at a relatively high resolution of $15 \mathrm{~m}$, which increased the chance for us to examine micro-variation over an area or between locations, and thus to enhance the quality of the model.

The results of this study contributed to an application that the $D^{2}$ modelling approach was useful to determine potential areas for new occurrences of Mimosa pigra. For Hoa Vang district, the presence of mimosa was likely to be related to decreasing values of $D^{2}$. Low $D^{2}$ values are not necessarily an indicator of mimosa presence. However, these low values indicate a higher probability of mimosa incursion in the corresponding locations.

In general, the results showed that the habitat conditions associated with mimosa occurrences were distinguishable from those of the null model locations as well as of the entire Hoa Vang district. In addition, the threshold value of 35.1 was effective in restricting potential areas for mimosa incursion (i.e. containing 99.5\% of existing mimosa occurrences). According to the threshold value, the percentage of area susceptible to mimosa occurrence 


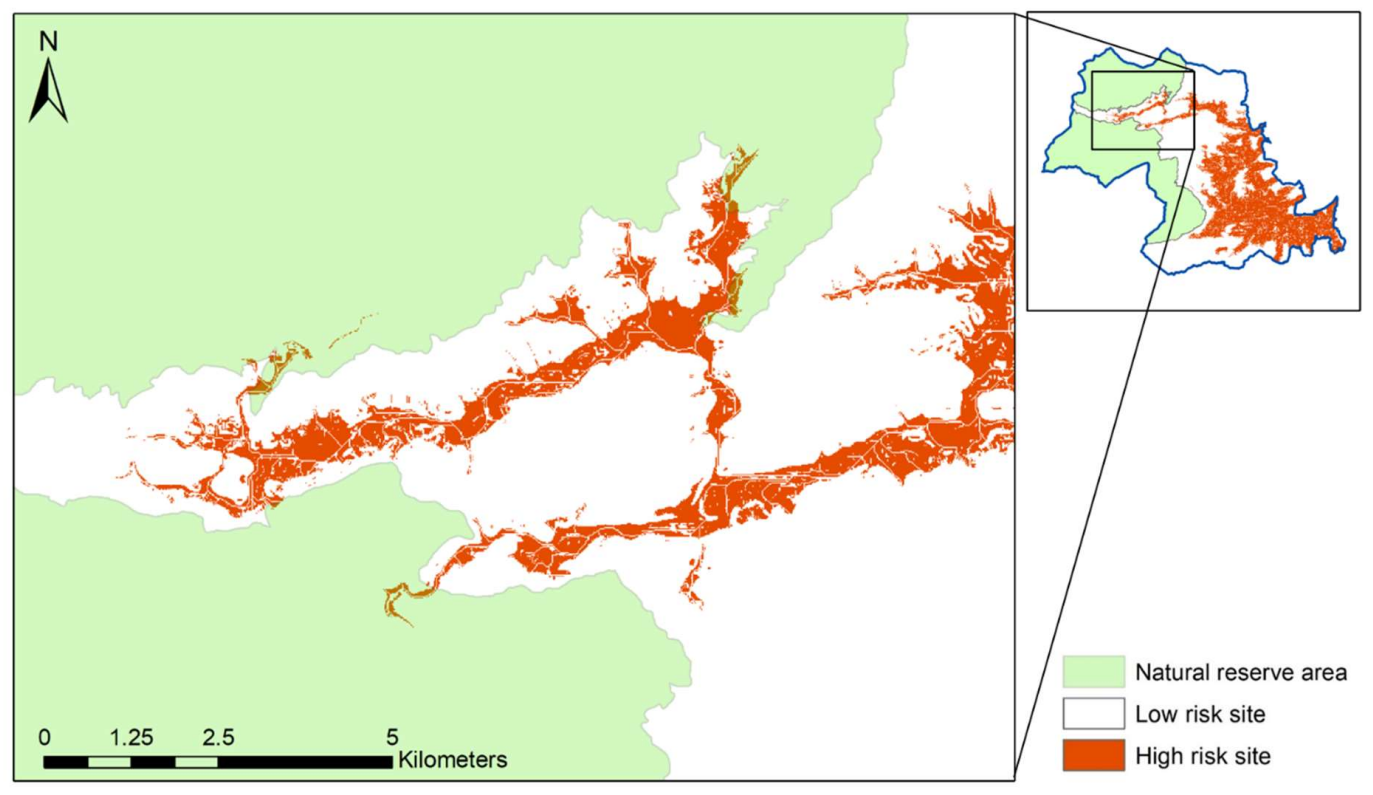

Figure 7. High-risk site of mimosa occurrence in $\mathrm{Ba} \mathrm{Na}$ - Nui Chua Natural Reserve.

was relatively large $(20.3 \%)$ which differs slightly from that percentage of locations in the null model $(17.6 \%)$. This result reveals the challenge facing the local land management in Hoa Vang district that may involve the invasive explosion of the super-alien Mimosa pigra.

Based on the results of the Mahalanobis distance model in this study, the requirement for the local authorities is to develop a plan of action in the high-risk area in order to early detect new occurrences of Mimosa pigra and eradicate them as soon as possible before any broad dispersal. The plan of action should include regular surveillance around high-risk areas, especially areas recently in disturbance, such as roadsides, stream banks, and construction sites. In addition to surveillance, a rapid response protocol should also be applied. Importantly, several areas with a high risk of Mimosa pigra occurrence distribute within or adjacent to the boundary of Ba $\mathrm{Na}$ - Nui Chua Nature Reserve in Hoa Vang district (Figure 7). Mimosa presence in these areas may cause more damage, especially to the local biodiversity and also to the function of the reserve. It is clear that correct predictions of the threat distribution can strongly support protection efforts. Hence, actions in these areas should be prioritized.

Last but not least, further detection of Mimosa pigra (i.e. from further regular surveillance) in Hoa Vang district would provide valuable empirical data, which are independent and reliable, for the model evaluation. These data can be used to rerun the model in this study to enhance its performance.

\section{Conclusions}

The Mahalanobis distance models in this study successfully generated a map determining potential areas for upcoming occurrences of the invasive plant Mimosa pigra. The high risk areas delineated by the model provide an important starting point for the local land managers to set up a plan of action in contribution to an early detection and rapid response protocol. Regular surveillance should be operated in high-risk areas, especially within 
or close to the local natural reserve in the study area to reduce the threat of mimosa to natural conservation. The spatial modelling techniques in this study can easily be applied to other species and areas, requiring appropriate environmental variables in connection with the presence of the corresponding species. High quality of environmental data in association with a set of accurate and verified observed locations would ensure the success of the application using this technique.

Acknowledgements. This work was supported by the Science and Technology Development fund (STDF) of the Danang University under the Ministry for Scientific Research, Danang, Vietnam grant number B2018.DNA.02.

\section{References}

Beven, K.J., Kirkby, M.J. 1979. A physically based, variable contributing area model of basin hydrology. - Hydrological Sciences Bulletin, 24(1), 43-69. DOI: 10.1080/02626667909491834.

Browning, D.M., Beaupre, S.J., Duncan, L. 2005. Using partitioned Mahalanobis $\mathrm{D}^{2}(\mathrm{k})$ to formulate a GIS-based model of timber rattlesnake hibernacula. - The Journal of Wildlife Management, 69(1), 33-44.

Cam, N.V., Lam, P.V., Dien, H.C., Huong, T.T., Hien, N.T. 1997. Biological control of giant sensitive plant Mimosa pigra L. in Vietnam. Report of ACIAR Project number 9313. Hanoi, National Institute for Plant Protection, VN Biological Control Research Center. 16 pp.

Clark, J.D., Dunn, J.E., Smith, K.G. 1993. A multivariate model of female black bear habitat use for a geographic information system. - Journal of Wildlife Management, 57(3), 519-526.

Da Nang People's Committee. 2018. Location and natural conditions. Da Nang city, Vietnam. [WWW document]. - URL https://danang. gov.vn. [Accessed 25 December 2018].

Elith, J., Phillips, S.J., Hastie, T., Dudík, M., Chee, Y.E., Yates, C.J. 2011. A statistical explanation of MaxEnt for ecologists. - Diversity and Distribution, 17, 43-57.

Engler, R., Guisan, A., Rechsteiner, L. 2004. An improved approach for predicting the distribution of rare and endangered species from occurrence and pseudo-absence data. Journal of Applied Ecology, 41(2), 263-274.
Fielding, A.H., Bell, J.F. 1997. A review of methods for the assessment of prediction errors in conservation presence/absence models. Environmental Conservation, 24(1), 38-49.

Guisan, A., Edwards, T.C., Hastie, T. 2002. Generalized linear and generalized additive models in studies of species distributions: setting the scene. - Ecological Modelling, 157(2-3), 89-100.

Higgins, S.I., Richardson, D.M., Cowling, R.M., Trinder-Smith, T.H. 1999. Predicting the landscape-scale distribution of alien plants and their threat to plant diversity. - Conservation Biology, 13, 303-313.

Hirzel, A.H., Hausser, J., Chessel, D., Perrin, N. 2002. Ecological-niche factor analysis: how to compute habitatsuitability maps without absence data. - Ecology, 83(7), 2027-2036.

Huberty, C.J. 1994. Applied Discriminant Analysis. New York, Wiley. 466 pp.

Hutchinson, G.E. 1957. Concluding remarks. Cold Spring Harbor Symposia on Quantitative Biology, 22(2), 415-427.

ISSG \& IUCN. 2017. Global invasive species database. Invasive Species Specialist Group and The International Union for Conservation of Nature. [WWW document]. - URL http:// www.iucngisd.org/gisd/. [Accessed 10 September 2017].

Jenness, J. 2009. Mahalanobis distances (mahalanobis.exe) extension for ArcGIS 9.x. Jenness Enterprises. [WWW document]. URL http://www.jennessent.com/arcview/ mahalanobis.htm. [Accessed 17 January 2019].

Jenness, J., Brost, B., Beier, P. 2013. Land facet corridor designer: extension for ArcGIS. Jenness Enterprises. [WWW document]. URL http://www.jennessent.com/arcgis/ land_facets.htm. [Accessed 17 January 2019].

Kvamme, K.L. 1992. A predictive site location model on the High Plains: an example with an independent test. - Plains Anthropologist 37, 19-40.

Lam, P.V., Son, N.H., Tan, T.Q., Dung, N.V., Khanh, P.H. 2001. Surveillance, evaluation of damage and proposals for effective control of Mimosa pigra in Nam Cat Tien and Tram Chim National Park. - Annual report. Hanoi, The National Institute of Plant Protection. 19 pp.

Le, B.T., Nguyen, T.L.T., Adkins, S. 2011. Damage caused by Merremia eberhardtii and Merremia boisiana to biodiversity of Da Nang city, Vietnam. - 23rd Asian-Pacific Weed Science Society Conference, Australia, September 2011. The Sebel Cairns, 161-169.

Le, T.S. 2018. A stratified GIS-based model to identify optimal locations for establishing new permanent sample plots for Eucalyptus bosistoana and Eucalyptus globoidea in New Zealand. - Master thesis. Christchurch (New Zealand), University of Canterbury. 90 pp.

Legenre P., Legendre, L. 1998. Numerical Ecology. Amsterdam, Elsevier Science. 852 pp. 
Liang, L., Clark, J.T., Kong, N., Rieske, L.K., Fei, S. 2014. Spatial analysis facilitates invasive species risk assessment. - Forest Ecology and Management, 315, 22-29.

Livingston, S.A., Todd, C.S., Krohn, W.B., Owen, R.B. 1990. Habitat models for nesting bald eagles in Maine. - Journal of Wildlife Management, 54(4), 644-653.

Lonsdale, W.M. 1992. The biology of Mimosa pigra. - Harley, K.L.S. (ed.). A Guide to the Management of Mimosa Pigra. Canberra, Commonwealth Scientific and Industrial Research Organisation, 8-32.

Manel, S., Dias, J.M., Buckton, S.T., Ormerod, S.J. 1999. Alternative methods for predicting species distribution: an illustration with Himalayan river birds. - Journal of Applied Ecology, 36, 734-747.

McCullagh, P., Nelder, J.A. 1989. Generalized Linear Models. London, Chapman and Hall. $532 \mathrm{pp}$.

MNRE \& MARD. 2013. Circular no. 27/2013/ TTLT-BTNMT-BNNPTNP. - The criteria for identifying invasive alien species and a list of invasive alien species. Hanoi, Ministry of Natural Resources and Environment and Ministry of Agriculture and Rural Development. 6 pp.

Pallewatta, N., Reaser, J.K., Gutierrez, A.T. 2003. Invasive alien species in south-southeast Asia: National reports and directory of resources. Cape Town, Global Invasive Species Programme. 111 pp.

Peeters, E.T.H.M., Gardeniers, J.J.P. 1998. Logistic regression as a tool for defining habitat requirements of two common gammarids. Freshwater Biology, 39(4), 605-615.

Pereira, J.M.C., Itami, R.M. 1991. GIS-based habitat modeling using logistic multiple regression: a study of the Mt. Graham red squirrel. Photogrammetric Engineering and Remote Sensing, 57(11), 1475-1486.

Peterson, A.T. 2001. Predicting species' geographic distributions based on ecological niche modeling. - The Condor: Ornithological Applications, 103(3), 599-605.

Pham, H.H. 1999. An Illustrated Flora of Vietnam. Ho Chi Minh, Tre Publishing House. 439 pp.

Phillips, S.J., Anderson, R.P., Schapire, R.E. 2006. Maximum entropy modeling of species geographic distributions. - Ecological Modelling, 190(3-4), 231-259.

Phillips, S.J., Dudík, M. 2008. Modeling of species distributions with Maxent: new extensions and a comprehensive evaluation. - Ecography, 31(2), 161-175.

R Core Team. 2013. R: A language and environment for statistical computing. $\mathrm{R}$ Foundation for Statistical Computing, Vienna, Austria. [WWW document]. - URL https://www.Rproject.org/. [Accessed 3 January 2019].
Rotenberry, J.T., Preston, K.L., Knick, S.T. 2002. A minimalist approach to mapping species' habitat: pearson's planes of closest fit. - Scott, J.M., Heglund, P.J., Morrison, M.L., Haufler, J.B., Raphael, M.G., Wall, W.A., Samson, F.B. (eds.). Predicting Species Occurrences: Issues of Accuracy and Scale. Washington DC, Island Press, 281-289.

Rotenberry, J.T., Preston, K.L., Knick, S.T. 2006. GIS-based niche modeling for mapping species' habitat. - Ecology, 87(6), 1458-1464.

Son, N.H., Lam, P.V., Cam, N.V., Thanh, D.V.T., Dung, N.V., Khanh, L.D., Forno, I.W. 2004. Preliminary studies on control of Mimosa pigra in Vietnam. - Julien, M., Flanagan, G., Heard, T., Hennecke, B., Paynter, Q., Wilson, C. (eds.). Research and Management of Mimosa pigra. Canberra, CSIRO Entomology, 110-116.

Spitz, F., Lek, S. 1999. Environmental impact prediction using neural network modelling: an example in wildlife damage. - Journal of Applied Ecology, 36(2), 317-326.

Tan, D.T., Thu, P.Q., Dell, B. 2012. Invasive plant species in the national parks of Vietnam. Forests, 3, 997-1016.

Thai, V.Q. 2016. The status, solutions and policies on the management of invasive alien species. - Technical report. Da Nang, Department of Agriculture and Rural Development. 112 pp.

Thanh, D.V.T., Cam, N.V., Thuy, L.T.T., Van, N.T., Hoat, T.X., Nguyen, N.H. 1998. Primary results of study on usage of Phloeospora mimosae pigrae to control giant sensitive plant Mimosa pigra. Annual report. Hanoi, The National Institute of Plant Protection. 7 pp.

Thompson, L.M., van Manen, F.T., Schlarbaum, S.E., DePoy, M. 2006. A spatial modeling approach to identify potential butternut restoration sites in Mammoth Cave National Park. - Restoration Ecology, 14(2), 289-296.

Thu, P.Q. 2003. Forest invasive species and their impacts on afforestation in Vietnam, the unwelcome guests. - The Asia-Pacific Forest Invasive Species Conference, China. Kunning, 17-23.

Triet, T., Kiet, L.C., Thi, N.T.L., Dan, P.Q. 2002. The invasion of Mimosa pigra in wetlands of the Mekong delta, Vietnam. - The 3rd International Symposium on the Management of Mimosa pigra, Australia. Canberra and Darwin, 45-51.

Triet, T., Thi, N.T.L., Storrs, M.J., Kiet, L.C. 2001. The value of awareness and early intervention in the management of invasive alien species: a case-study on the eradication of Mimosa pigra at the Tram Chim National Park. - The Convention on Biological Diversity, Canada. Montreal, 37-38.

Tsoar, A., Allouche, O., Steinitz, O., Rotem, D., Kadmon, R. 2007. A comparative evaluation of presence-only methods for modelling species distribution. - Diversity and Distribution, 13(4), 397-405. 
Tucker, C.J. 1979. Red and photographic infrared linear combinations for monitoring vegetation. - Remote Sensing of Environment, 8(2), 127150.

USDA Forest Service. 2003. A National Early Detection and Rapid Response System for Invasive Plants in the United States: Federal Interagency Committee for the Management of Noxious and Exotic Weeds. Washington DC, United States Department of Agriculture. $28 \mathrm{pp}$.

van Manen, F.T., Clark, J.D., Schlarbaum, S.E., Johnson, K., Taylor., G. 2002. A model to predict the occurrence of surviving butternut trees in the southern Blue Ridge Mountains. - Scott, J.M., P.J. Heglund, M.L. Morrison (eds.). Symposium on Predicting Species Occurrences: Issues of Scale and Accuracy. Covelo, Island Press, 491-497.

van Manen, F.T., Young, J.A., Thatcher, C.A., Cass, W.B., Ulrey, C. 2005. Habitat models to assist plant protection efforts in Shenandoah National Park, Virginia, USA. - Natural Areas Journal, 25(4), 339-350.
Vietnam Government. 2014. Decision 1976/QDTTg: Approving the planning for special-use forest system across the country to the year 2020, and a vision to 2030. Hanoi, Vietnam Government, 19-30.

Walden, D., Finlayson, C.M., van Dam, R., Storrs, M. 1999. Information for a risk assessment and management of Mimosa pigra in Tram Chim National Park, Vietnam. - The EnviroTox'99 International Conference, Australia. Royal Australian Chemical Institute, 160-170.

Zaniewski, A.E., Lehmann, A., Overton, J.McC. 2002. Predicting species spatial distributions using presence-only data: a case study of native New Zealand ferns. - Ecological Modelling, 157(2-3), 261-280.

Received April 18, 2019, revised May 15, 2019, accepted September 6, 2019 